\title{
Effects of Simvastatin on Alveolar Regeneration and Its Relationship to Exposure in Mice with Dexamethasone-Induced Emphysema
}

\author{
Shihomi Hirooka, Misaki Ueno, Satoko Fukuda, Atsushi Miyajima, ${ }^{\dagger}$ and Takashi Hirota* \\ Department of Biopharmaceutics, Faculty of Pharmaceutical Sciences, Tokyo University of Science; 2641 Yamazaki, \\ Noda, Chiba 278-8510, Japan. \\ Received August 4, 2016; accepted November 24, 2016
}

In the present study, the relationship between systemic exposure of simvastatin (SV) hydroxy acid (SVacid), an active form of SV, and its alveolar regeneration rates was investigated using emphysema model mice created by postnatal treatment of dexamethasone. In a model with young animals, the mice were treated with SV for $10 \mathrm{~d}$ from postnatal day 42 . Similar alveolar regeneration with a \% mean linear intercept $\left(L_{\mathrm{m}}\right)$ recovery of 60 to $70 \%$ by histochemical observation was observed in mice after intraperitoneal administration at dose in the range of $4-100 \mu \mathrm{g} / \mathrm{mouse}$. The $\% L_{\mathrm{m}}$ recovery after oral administration of $20 \mu \mathrm{g} / \mathrm{mouse}$ was comparable with that after intraperitoneal administration at a dose of $4 \mu \mathrm{g} / \mathrm{mouse}$, when their exposure of $\mathrm{SV}$-acid was almost similar in both treated groups. Regardless of the route of administration, the recovery can depend on the exposure level of SV-acid, and to the maximum was about $60-70 \%$. On the other hand, in a model with adult animals, the mice were intraperitoneally administrated SV at a dose of $4 \mu \mathrm{g} / \mathrm{mouse}$ for $10 \mathrm{~d}$ from postnatal day 152 . Compared to young animals, less $\% L_{\mathrm{m}}$ recovery was observed in adult mice even their systemic exposures of SV-acid were similar.

Key words simvastatin; pharmacokinetics; alveolar regeneration; mouse

Emphysema is one of the two major symptoms of chronic obstructive pulmonary disease (COPD), and is characterized by irreversible destruction of the alveolar walls caused by chronic exposure to toxic substances such as cigarette smoke and polluted air. In consequence, since alveoli are enlarged abnormally and their surface area is decreased, the gas exchange capacity is markedly reduced. Therefore, pulmonary function impairment develops with some symptoms such as cough, abnormal sputum, shortness of breath and/or difficulty breathing. In general, once alveoli are damaged, it is extremely difficult for them to recover. As one of the main reasons, there is a very slow turn-over of elastin, which is an essential component of alveoli for their elasticity. At the present time, only symptomatic therapies such as bronchodilator and expectorant agents and/or oxygen inhalation as supportive care are available. Thus, development of a basic remedy for emphysema is strongly desired.

It has been reported that regeneration of alveoli can be induced in rodents by treatment with some compounds, such as adrenomedullin, ${ }^{1)}$ granulocyte-colony stimulating factor, ${ }^{2)}$ tamibarotene $^{3)}$ and all-trans-retinoic acid. ${ }^{4)}$ In 2005, Lee et al. reported that simvastatin (SV) inhibited lung parenchymal destruction induced by cigarette smoking. ${ }^{5)}$ In addition it was reported that similar regeneration was observed by treatment with SV in mice with elastase. $\left.{ }^{6}\right) \mathrm{SV}$ is one of the statins, which are widely used as medication for treating hypercholesterolemia and cardiovascular diseases. In addition, it was reported that the active form of $\mathrm{SV}$, simvastatin hydroxy acid (SV-acid), ${ }^{7)}$ partially protected against muscle weakness after massive rotator cuff tear in rats, ${ }^{8)}$ affected the expression of heme oxygenase- 1 in mice ${ }^{9)}$ and inhibited the induction of matrix metalloproteinase- 9 in rats. ${ }^{10)}$ Moreover it had an anti-

\footnotetext{
${ }^{\dagger}$ Present address: Department of Biopharmaceutics, Meiji Pharmaceutical University; 2-522-1 Noshio, Kiyose, Tokyo 204-8588 Japan.
}

inflammatory action and promoted epithelial cell proliferation. ${ }^{5)}$ These effects suggested the possibility that statins may be a basic remedy for emphysema. Actually it was reported that the statin use was partially associated with a slow decline in pulmonary function in smokers and former smokers, ${ }^{11)}$ and also with a reduction in mortality in COPD patients. ${ }^{12)}$ However, there are few reports demonstrating the relationship between the alveolar regeneration by SV and exposure levels in plasma and lungs. Thus we cannot estimate whether SV would be useful clinically for the treatment of emphysema at the approved dose and dosing route.

In this study, using the dexamethasone (Dex)-induced model of emphysema in mice, we revealed the relationship between the regeneration rate and pharmacokinetics of SV. In particular, the association between the doses and routes of administration and the regeneration were investigated, and also effects in young and adult mice were compared.

\section{MATERIALS AND METHODS}

Chemicals and Reagents SV was purchased from Tokyo Chemical Industries, Ltd. (Tokyo, Japan). SV-acid ammonium salt, Dex and lovastatin hydroxy acid (LV-acid) sodium salt were purchased from Wako Pure Chemical Industries, Ltd. (Osaka, Japan). All other reagents and solvents in this study were obtained commercially and were either extra pure, molecular biology or biochemical grade.

Animals Pregnant ICR mice (day 14 of gestation) were obtained from CLEA Japan, Inc. (Tokyo, Japan). Their male offspring were used for alveolar regeneration experiments, and postnatal day 1 (P1) was defined as the first day after birth, consistent with our previous study about the effects of all-trans retinoic acid on alveolar regeneration. ${ }^{13,14)}$ Male ICR mice ( 6 weeks old) were obtained also from the same breeder and used for pharmacokinetic (PK) experiments after 5 or 
more days of acclimatization. All mice were housed in a temperature- $\left(23 \pm 1^{\circ} \mathrm{C}\right)$ and humidity- $(55 \pm 5 \%)$ controlled room with 12-h light/dark cycle. Water and food were available ad libitum for all experiments except for the PK experiment as described below. The protocols were approved by the institutional review committee in the Tokyo University of Science as animal experiment protocols No. Y14005 and Y14036. All experimental animals were handled in accordance with the institutional and national guidelines for the care and use of laboratory animals.

Preparation of the Drug Solutions A solution of $20 \mu \mathrm{g}$ per milliliter of Dex for the intraperitoneal (i.p.) administration was prepared as described previously by Kamei et al. ${ }^{13)}$ Briefly Dex was dissolved in dimethylsulfoxide and diluted with phosphate buffered saline ( $\mathrm{pH}$ 7.4) up to 200-fold. All of the bottles and tubes containing Dex were covered by aluminum foil to prevent exposure to light and were stored at $4^{\circ} \mathrm{C}$ until use. SV solution for intraperitoneal and oral administration was prepared as follows; SV was dissolved in ethanol to a final concentration of $50 \mathrm{mg} / \mathrm{mL}$, and diluted with peanut oil to $1.0,0.2$, and $0.04 \mathrm{mg} / \mathrm{mL}$. All of the formulations containing SV were prepared just before use.

Creation of Dex-Induced Model of Emphysema in Mice According to our previous reports, ${ }^{13,14)}$ newborn male mice in the emphysema group were subcutaneously administered Dex solution at a dose of $0.4 \mu \mathrm{g} /$ mouse $(20 \mu \mathrm{L}$ injection) from P3 to P14 daily with a 2-d break on P8 and P9. Only vehicle was administered to mice in the control group.

\section{Alveolar Regeneration Experiments}

Dose Proportionality

Mice with induced emphysema were allocated to 4 groups ( $n=4$ in each group), designated the 4-SV, 20-SV, 100-SV, and Dex groups. The mice in the 4-SV, 20-SV, and 100-SV groups were i.p. administered SV at doses of 4, 20 and $100 \mu \mathrm{g} /$ mouse/d, respectively, from P42 to P53 daily with a 2-d break on P47 and P48. Only vehicle was administered to mice in the Dex and control (not induced emphysema, $n=4$ ) groups. At P90 the lungs were isolated from the mice after euthanasia by exsanguination under isoflurane anesthesia, and were used for the evaluation of alveolar regeneration.

Effect of Administration Route

Mice with induced emphysema were allocated to 4 groups ( $n=5$ in each group), designated 4-SV-i.p., 4-SV-per os (p.o.), 20-SV-p.o. and Dex groups. The mice in the 4-SV-i.p., 4-SVp.o. and 20-SV-p.o. groups were administered SV at the doses of $4 \mu \mathrm{g} / \mathrm{mouse} / \mathrm{d}$ i.p., 4 and $20 \mu \mathrm{g} / \mathrm{mouse} / \mathrm{d}$ orally, respectively, from P42 to P53 daily with a 2 -d break on P47 and P48. Only vehicle was administered to mice in the Dex and control $(n=5)$ groups. At P90 ( $37 \mathrm{~d}$ after completion of SV treatment) the lungs were isolated as described above.

In Adult Mice

Mice with induced emphysema were allocated to 2 groups ( $n=4$ in each group), designated $4-\mathrm{SV}$ and Dex groups. The mice in 4-SV group were administered SV at a dose of $4 \mu \mathrm{g}$ / mouse/d i.p. from P152 to P163 daily with a 2-d break on P157 and P158. Only vehicle was administered to mice in Dex and control $(n=4)$ groups. At P200 (37 d after completion of SV treatment) the lung was isolated as described above.

Chronological Changes of Alveoli New born mice (male) were allocated into 3 groups: control $(n=10)$, Dex $(n=10)$, and SV $(n=20)$. The creation of Dex-induced model of emphysema and the treatment with $\mathrm{SV}(4 \mu \mathrm{g} /$ mouse, i.p.) were conducted in the same manner as described above. At P38, the lungs were isolated from 5 mice each in the control $(n=4)$ and Dex groups as described above. At P48, 55, and 63, the lungs were also isolated from 5 mice in SV group at each time point.

PK Experiments Male mice (6 weeks old) were allocated into 3 groups ( $n=6$ in each group). The mice in each group were administered SV intraperitoneally at a dose of $4 \mu \mathrm{g}$ / mouse or orally at doses of 4 or $20 \mu \mathrm{g} /$ mouse. In addition, 5 mice (21 weeks old) were intraperitoneally administered SV solution at a dose of $4 \mu \mathrm{g} /$ mouse. At 0 (predose), 15, 30, $45,60,90,120,240$, and $360 \mathrm{~min}$ after the administration, blood was collected from the tail vein with a hematocrit tube. Blood samples were centrifuged at $3000 \times \boldsymbol{g}$ at $4^{\circ} \mathrm{C}$ for $10 \mathrm{~min}$ to obtain plasma. The plasma was frozen at $-80^{\circ} \mathrm{C}$ until the measurement of SV-acid concentration, which was conducted within a week after collecting the samples.

Histopathological Analyses Lung sections were prepared and alveolar mean linear intercept $\left(L_{\mathrm{m}}\right)$ was calculated according our previous report. ${ }^{13)}$ The $L_{\mathrm{m}}$ was calculated from the images of the sections using image analyses software, Image J (National Institutes of Health, U.S.A.), as an index of the distance between alveolar walls, according to previous study by Dunnill. ${ }^{15)}$ The $\% L_{\mathrm{m}}$ recovery was calculated as an index of alveolar regeneration by $\mathrm{SV}$ using following equation as described previously; \% of $L_{\mathrm{m}}$ recovery $=\left[\left(L_{\mathrm{m}, \text { Dex }}-L_{\mathrm{m}, \mathrm{SV}}\right) /\left(L_{\mathrm{m}, \text { Dex }}-\right.\right.$ $\left.\left.L_{\text {m,control }}\right)\right] \times 100$. The subscript notation of $L_{\mathrm{m}}$ shows the group name.

Determination of SV-Acid Concentration in Plasma and Lungs According to the method of Germershausen et al., ${ }^{16)}$ plasma samples were pretreated as described below. A four-fold volume of acetonitrile containing $10 \mathrm{ng} / \mathrm{mL}$ of LV-acid (internal standard) was added to thawed plasma, and the mixture was centrifuged at $10800 \times \boldsymbol{g}$ at $4^{\circ} \mathrm{C}$ for $10 \mathrm{~min}$ to precipitate the proteins. Then, the supernatant was applied to API3200 ${ }^{\mathrm{TM}} \mathrm{LC}-\mathrm{MS} / \mathrm{MS}$ system (ABSciex, MA, U.S.A.).

The LC was performed on a model 20-A Prominence system (Shimadzu Corporation, Kyoto, Japan) equipped with a Sunfire ${ }^{\mathrm{TM}} \mathrm{C}_{18}$ column $(2.1 \times 50 \mathrm{~mm}$, i.d. $3.5 \mu \mathrm{m}$, Waters, MA, U.S.A.). The column temperature was set at $40^{\circ} \mathrm{C}$. Solvent A was $0.1 \%(\mathrm{v} / \mathrm{v})$ formic acid aqueous solution. Solvent B was acetonitrile $(t=0-1.0 \mathrm{~min}, 10 \%$ acetonitrile; $t=1.1-1.6 \mathrm{~min}$, $95 \%$ acetonitrile; $t=1.7-8.0 \mathrm{~min}, 10 \%$ acetonitrile). The flow rate was $0.3 \mathrm{~mL} / \mathrm{min}$. Injection volume was $15 \mu \mathrm{L}$. Tandem mass spectrometry was performed using an API $3200^{\mathrm{TM}}$ tandem quadrupole MS system (ABSciex) with negative ion electrospray ionization,). The precursor $\rightarrow$ product ions monitored were $\mathrm{m} / \mathrm{z} \quad 421.2 \rightarrow 101.1$ (LV-acid) and $\mathrm{m} / \mathrm{z} \quad 435.3 \rightarrow 319.2$ (SV-acid).

Pharmacokinetics Analyses Pharmacokinetics of SV in plasma were characterized by determining the peak concentration $\left(C_{\max }\right)$, time to $C_{\max }\left(T_{\max }\right)$ and area under the concentration-time curve $(A U C)$ from time zero to last measurable time point $\left(A U C_{0-\text { last }}\right)$ after single administration of $\mathrm{SV}$. The $C_{\max }$ and $T_{\max }$ values were taken directly from the data. $A U C_{0-\text { last }}$ was calculated by the linear trapezoidal rule.

Statistical Analysis As statistical analyses, Tukey's and Dunnett's multiple comparison tests and Student's $t$-tests were used to determine the statistical significance using SPSS 17.0 (IBM, Armonk, NY, U.S.A.). Differences were considered statistically significant when $p<0.05$. 
A)

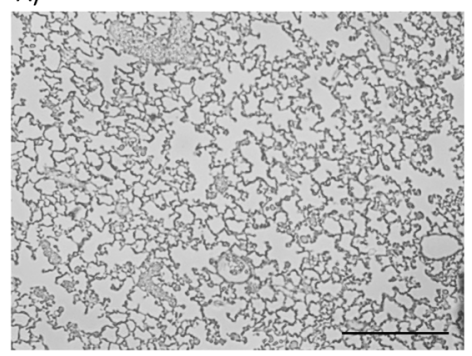

B)

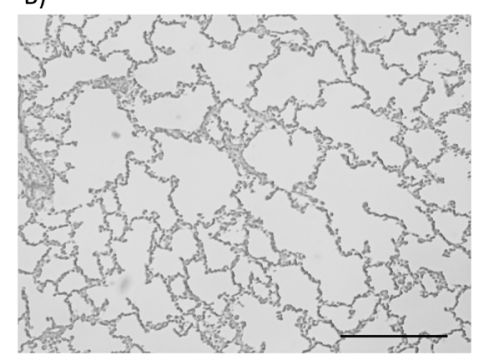

C)

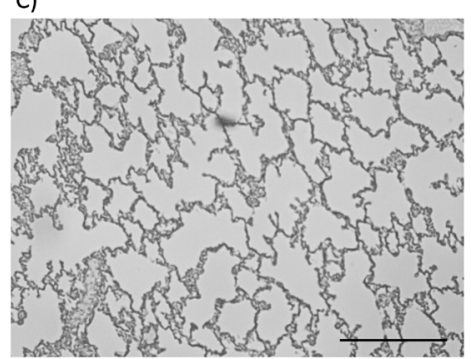

Fig. 1. Representative Micrographs of Lungs from Various Treatments

A): Control group, B): Dex group, C): 4-SV group, given $4 \mu \mathrm{g} / \mathrm{mouse}$ of SV (i.p.) for $10 \mathrm{~d}$. At P90 the lungs sections were prepared, and the sections were stained with Elastica-van Gieson. Original magnification, $100 \times$. Bars, $200 \mu \mathrm{m}$.

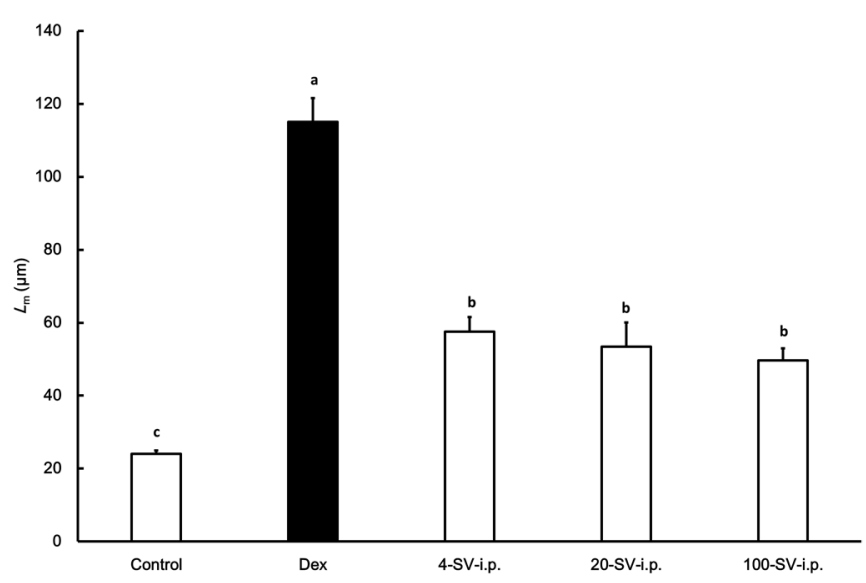

Fig. 2. Effects of SV Dosage on Alveolar Regeneration in Young Mice

Zero (only peanut oil as a vehicle), 4,20 or $100 \mu \mathrm{g} / \mathrm{mouse} / \mathrm{d}$ SV was administered intraperitoneally for $10 \mathrm{~d}$ to the mice with induced emphysema in the Dex, 4-SV $20-\mathrm{SV}$ and 100-SV groups, respectively. $L_{\mathrm{m}}$ was calculated from lung sections from each mouse as an index of the alveolar size. Data are shown as the mean \pm S.D. $n=4$. Letters over the bars indicate results of the pairwise comparison as shown in the following sentence. The means are significantly different $(p<0.05$, Tukey's multiple comparison test) for pairs of bars with different characters.

\section{RESULTS}

\section{Alveolar Regeneration Experiments}

Dose Proportionality after Intraperitoneal Administration

To confirm the alveolar regeneration by SV and to further investigate its dose-proportionality, histological analysis of the lung sections was performed. The mice were intraperitoneally administered at doses of 4,20 , and $100 \mu \mathrm{g}$ of SV/mouse/d on the above mentioned schedule. The alveoli in lung sections from mice in the SV treated group were smaller than those in Dex group (Fig. 1), but still larger than those in the control group. The average $L_{\mathrm{m}}$ of each of the 3 different dosage groups was 48 to $58 \mu \mathrm{m}$, and significantly shorter than that of the Dex group (about $115 \mu \mathrm{m}$ ) (Fig. 2), and the $\% L_{\mathrm{m}}$ recovery was $63-72 \%$. However, there were no significant differences of $L_{\mathrm{m}}$ among the 3 dosage groups, indicating no dose-proportionality within that dose range.

After Oral Administration

The mice were administered intraperitoneally at a dose of 4 (4-SV-i.p.) and orally at the doses of 4 and $20 \mu \mathrm{g} / \mathrm{mouse} / \mathrm{d}$ (4-SV-p.o. and 20-SV-p.o., respectively) of SV on the above mentioned schedule. Smaller alveoli were observed in the mice in the 4-SV-i.p. and 20-SV-p.o. groups than in the Dex group (Fig. 3), and the $L_{\mathrm{m}}$ of these SV-treated groups were significantly shorter than that of the Dex group $(p<0.05)$. In

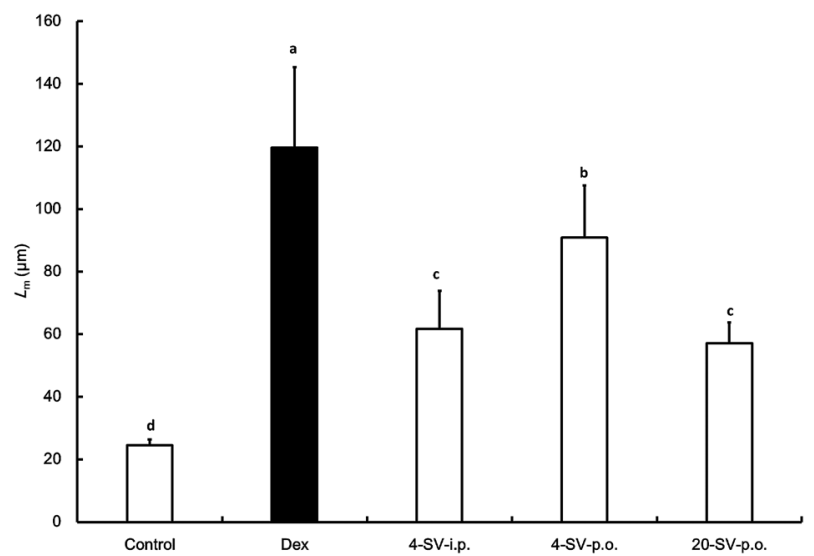

Fig. 3. Effects of Administration Route of SV on Alveolar Regeneration in Young Mice

Four and $20 \mu \mathrm{g} / \mathrm{mouse} / \mathrm{d}$ of SV was administered intraperitoneally for $10 \mathrm{~d}$ to mice with induced emphysema in 4-SV-i.p. group. Also 4 and $20 \mu \mathrm{g} / \mathrm{mouse} / \mathrm{d}$ of SV was administered orally to the mice in 4-SV-p.o. and 20-SV-p.o. groups, respectively. Then the $L_{\mathrm{m}}$ was calculated from lung sections from each mouse as an index of the alveolar size. Data are shown as the mean \pm S.D., $n=5$. Letters over the bars indicate results of the pairwise comparison as shown in the following sentence. The means are significantly different $(p<0.05$, Tukey's multiple comparison test) for pairs of bars with different characters.

the 4-SV-p.o. group, although the alveoli looked smaller their $L_{\mathrm{m}}$ was not significantly shorter than that of the Dex group (Table 1).

Chronological Changes of Alveoli For the evaluation on the process of alveolar regeneration, the lung sections in the SV group were observed for chronological changes on a few points from the day just before the start of treatment (P38) to the day for final evaluation (P93). At $10 \mathrm{~d}$ after the start, $L_{\mathrm{m}}$ in the treatment group began to decrease (Fig. 4). Finally, at P93 the $\% L_{\mathrm{m}}$ recovery was 79.3 in $\mathrm{SV}$ group.

In Adult Mice To clarify whether the effect on alveolar regeneration by SV was different between young and adult mice, similar experiments were also conducted using adult mice. In adult mice, $L_{\mathrm{m}}$ after intraperitoneal administration of SV at a dose of $4 \mu \mathrm{g} /$ mouse tended to be smaller than that in the Dex group, but the difference was not significant (Fig. 5). The $\% L_{\mathrm{m}}$ recovery of alveoli in the adult mice was weaker than that observed in young mice as described above (Table 1). Meanwhile the mean alveolar length in adult mice in the Dex group were significantly larger than those in the control group $(p<0.05)$. The $L_{\mathrm{m}}$ in adult mice in the Dex and control groups were relatively shorter and longer, respectively, than that in young mice (Fig. 5).

Exposure of SV-Acid in Normal Mice 


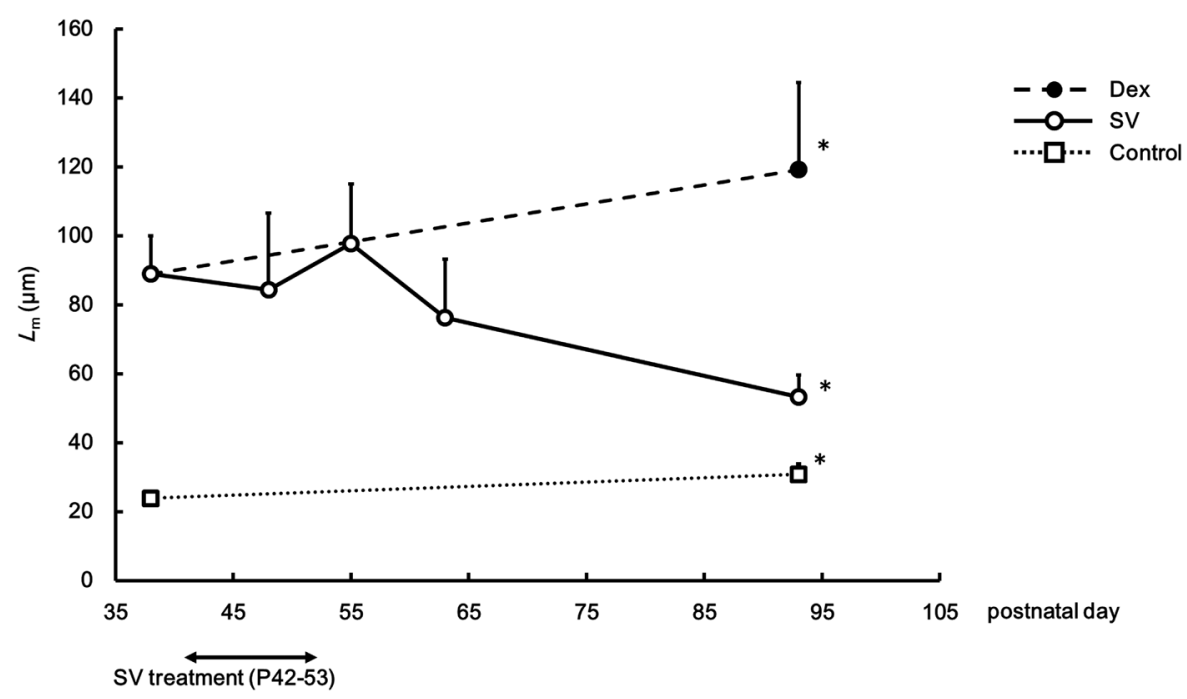

Fig. 4. Chronological Changes of Alveolar Regeneration after SV Treatment

Zero (only peanut oil as a vehicle) and $4 \mu \mathrm{g}$ /mouse/d SV was administered intraperitoneally for $10 \mathrm{~d}$ to the mice with induced emphysema in the Dex and SV groups, respectively. Mice in control group were without any treatment. Then the $L_{\mathrm{m}}$ was calculated from lung sections from each mouse as an index of the alveolar size. Data are shown as the mean \pm S.D., $n=5$. * indicates significant difference compared to the $L_{\mathrm{m}}$ at P38 in each Dex and control group detected by Student's $t$-tests and in SV group detected by Dunnett's multiple comparison tests, respectively $(p<0.05)$.

Table 1. Comparison of Changes of Alveoli after Treatment with SV in Young and Adult Mice

\begin{tabular}{ccl}
\hline \hline Age & $\% L_{\mathrm{m}}$ Recovery & \multicolumn{1}{c}{ Objective of the study } \\
\hline Young (P90) & 63.2 & Dose proportionality \\
Young (P90) & 61.0 & Administration route \\
Young (P93) & 74.6 & Chronological changes of alveoli \\
Adult (P200) & 40.3 & Adult mice \\
\hline
\end{tabular}

Data are shown as the mean, $n=4$ or 5 . The $\% L_{\mathrm{m}}$ recovery (after $4 \mu \mathrm{g} /$ mouse of $\mathrm{SV}$, i.p.) was calculated from the studies about dose proportionality, the administration route and chronological changes of alveoli, and the study in adult mice, respectively. i.p.; intraperitoneal administration.

\section{In Young Mice}

To investigate systemic exposure of SV under various administration conditions, young normal mice were administered intraperitoneally at $4 \mu \mathrm{g} /$ mouse and orally at 4 and $20 \mu \mathrm{g} /$ mouse and their pharmacokinetic parameters of SV-acid were calculated (Fig. 6, Table 2). The concentrations in plasma reached the maximum at about $30 \mathrm{~min}$ after dosing for both routes of administration and either dose. The $A U C_{0-\text { last }}$ after intraperitoneal administration at $4 \mu \mathrm{g} /$ mouse and oral administration at $20 \mu \mathrm{g} /$ mouse were comparable. However, that after oral administration at $4 \mu \mathrm{g} /$ mouse tended to be lower than those of the other two groups.

In Adult Mice

To investigate whether there was a difference in systemic exposure between young and adult mice, $4 \mu \mathrm{g} /$ mouse of SV was administered intraperitoneally to normal adult mice for calculation of their pharmacokinetics of SV-acid (Fig. 6, Table 2). There was no significant difference in $A U C_{0 \text {-last }}$ between young and adult mice.

\section{DISCUSSION}

There have been a few reports that SV inhibited alveolar destruction $^{5)}$ and affected alveolar recovery ${ }^{6}$ in emphysema model animals. In this study, SV was revealed to have effects

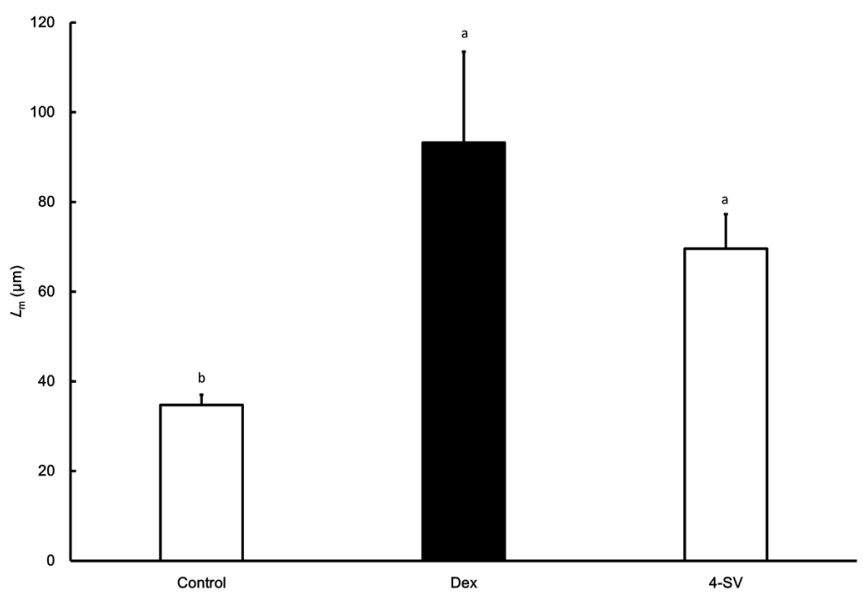

Fig. 5. Effects of SV on Alveolar Regeneration in Adult Mice

Zero (only peanut oil as a vehicle) and $4 \mu \mathrm{g} / \mathrm{mouse} / \mathrm{d}$ of SV was administered intraperitoneally for $10 \mathrm{~d}$ (from P152 to P163) to the mice with induced emphysema in the Dex and 4-SV groups, respectively. Then the $L_{\mathrm{m}}$ was calculated from lung sections from each mouse at P200 as an index of the alveolar size. Data are shown as the mean \pm S.D., $n=6$. Letters over the bars indicate results of the pairwise comparison as shown in the following sentence. The means are significantly different ( $p<0.05$, Tukey's multiple comparison test) for pairs of bars with different characters.

also in a Dex-induced model of emphysema, which is an alveolar hypoplastic model, indicating the effect of SV was not dependent on mechanism for production of alveolar damage in the model. After intraperitoneal administration of SV to model mice in the dose range of 4 to $100 \mu \mathrm{g} / \mathrm{mouse} / \mathrm{d}$, alveolar regeneration with $\% L_{\mathrm{m}}$ recovery of $63-72 \%$ was clearly observed in each group (Figs. 1, 2). These results indicated that there was no clear dose-proportionality in this dose range and a limit of alveolar recovery was up to $60-70 \%$ at least for a Dex-induced model. Furthermore, it is suggested that the intraperitoneal administration of $4 \mu \mathrm{g} / \mathrm{mouse} / \mathrm{d}$ was sufficient for this treatment.

$\mathrm{SV}$ is used clinically as an oral formulation. Thus, it is important to determine whether the same effect can be obtained with clinically feasible oral doses of SV. As the beginning, 


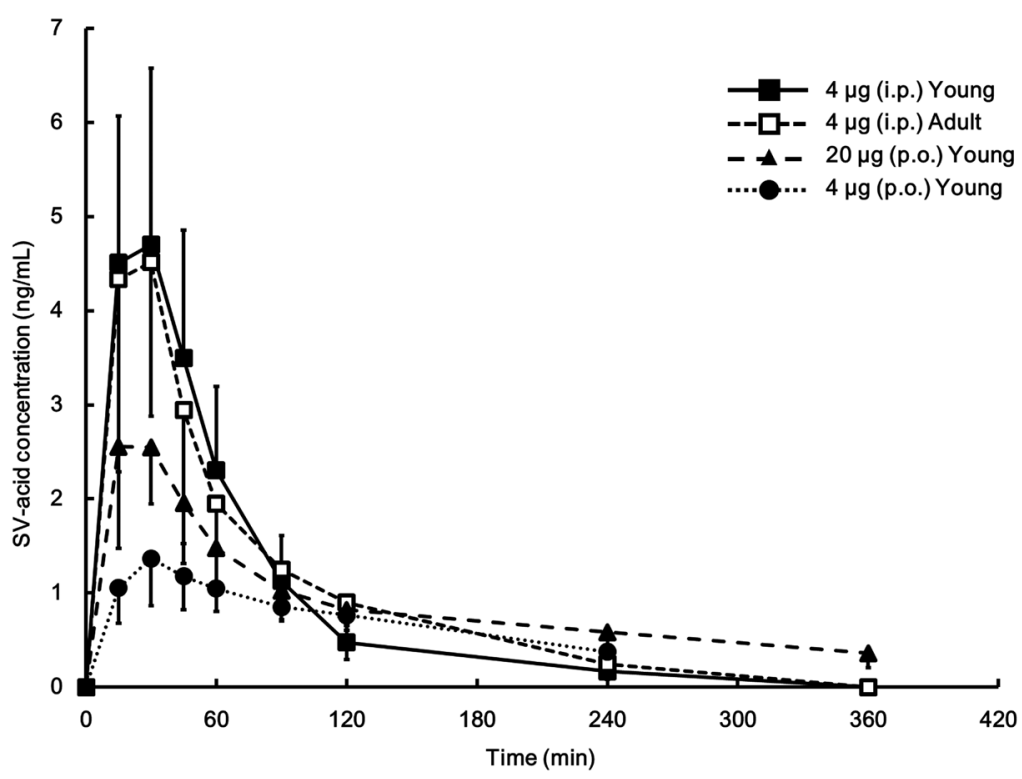

Fig. 6. Time Course of SV-Acid Concentration in Plasma

Four microgram/mouse of SV was administered i.p. to young (filled square) or adult mice (open square), and orally to young mice (closed circle). Twenty microgram/ mouse of SV was administered orally to young mice (closed triangle). Data are shown as the mean \pm S.D., $n=5$ (adult) or 6 (young).

Table 2. PK Parameters of SV-Acid in Mice under Various SV Administration Conditions

\begin{tabular}{cccccc}
\hline \hline Age (Young/Adult) & Dose $(\mu \mathrm{g} /$ mouse $)$ & Administration route & $C_{\max }(\mathrm{ng} / \mathrm{mL})$ & $T_{\max }(\min )$ & $A U C_{0-\text { last }}(\mathrm{ng} \cdot \mathrm{min} / \mathrm{mL})$ \\
\hline Adult & 4 & i.p. & $4.7 \pm 1.8^{\mathrm{a}}$ & $24.0 \pm 8.2^{\mathrm{a}}$ & $355.2 \pm 164.5^{\mathrm{a}}$ \\
Young & 4 & i.p. & $4.8 \pm 1.6^{\mathrm{a}}$ & $22.5 \pm 8.2^{\mathrm{a}}$ & $332.0 \pm 136.9^{\mathrm{a}}$ \\
Young & 4 & p.o. & $1.4 \pm 0.5^{\mathrm{b}}$ & $37.5 \pm 8.2^{\mathrm{a}}$ & $194.9 \pm 44.9^{\mathrm{a}}$ \\
Young & 20 & p.o. & $2.8 \pm 0.9^{\mathrm{a}, \mathrm{b}}$ & $25.0 \pm 12.2^{\mathrm{a}}$ & $323.5 \pm 29.4^{\mathrm{a}}$ \\
\hline
\end{tabular}

Data are shown as the mean \pm S.D., $n=5$ (adult) or 6 (young). i.p., intraperitoneally; p.o., oral per os; $C_{\text {max }}$, peak concentration; $T_{\text {max }}$, time to $C_{\text {max }} ; A U C_{0}$, area under the concentration-time curve from time zero to last measurable time point. Superscript characters indicate results of the pairwise comparison as shown in the following sentence. The means with different superscript characters are significantly different $(p<0.05$, Tukey's multiple comparison test) for pairs of values with different characters.

whether it was possible to obtain an exposure of SV-acid after oral administration that would be similar to that resulting in alveolar recovery was investigated and also the required dose was investigated. As the result, the exposure in plasma after oral administration of SV at $20 \mu \mathrm{g} /$ mouse was comparable to that after intraperitoneal administration at $4 \mu \mathrm{g} / \mathrm{mouse}$ (Fig. 6, Table 2). As a matter of fact, the alveolar recovery after these treatments with SV was also comparable (Fig. 3). However, after oral treatment at $4 \mu \mathrm{g} /$ mouse the alveoli only recovered slightly, when the exposure to SV-acid in plasma was less than half of that after the effective doses. From the results, regardless of the route of administration, almost maximum recovery can be obtained after treatment by SV when the plasma exposure is equal to or higher than that after intraperitoneal administration at a dose of $4 \mu \mathrm{g} / \mathrm{mouse}$. On the other hand, the $A U C$ of SV-acid in the mice $(20 \mu \mathrm{g} /$ mouse p.o., $4 \mu \mathrm{g} /$ mouse i.p.) in the present study was a little higher or comparable to that after administered $20 \mathrm{mg}$ of SV to human volunteers, ${ }^{17}$ which is within the range of a clinical daily dose of SV in humans $(2.5-20 \mathrm{mg} / \mathrm{d})$. If the sensitivity to simvastatin in humans is similar to that in mice, clinical application of SV for the treatment of emphysema could be possible.

Next, the time-course of alveolar recovery was investigated after intraperitoneal administration of SV at a dose of $4 \mu \mathrm{g}$ / mouse to young model mice. Based on analysis of the lung tissue sections, reduction of $L_{\mathrm{m}}$ value began $10 \mathrm{~d}$ after the completion of the administration of SV, and continued until the end of observation period, P90 (Fig. 4). These results revealed that the effect of SV could be maintained not only in the treatment period for $10 \mathrm{~d}$ but also after that period.

It is well known that emphysema often occurs in middleaged and elderly persons rather than in young ones because it is a respiratory disease mainly caused by long-term smoking. So, the evaluation for therapy of emphysema needs to use not only a model in young animals but also especially a model in adult animals. Using adult-model mice, the alveolar recovery after intraperitoneal administration of $\mathrm{SV}$ at a dose of $4 \mu \mathrm{g} /$ mouse for $10 \mathrm{~d}$ from P150. After the treatment of SV the alveoli tended to recover, but the effect was weaker than in young model mice (Fig. 5, Table 1). Meanwhile, no significant difference of plasma concentration profile or exposure was observed between the young (6 week old) and adult (21 week old) mice after the intraperitoneal administration (Fig. 6, Table 2), even though the dose on a $\mu \mathrm{g} / \mathrm{kg}$ basis in adult mice was lower because of the difference in body weights. From these results, the sensitivity to alveolar recovery by SV might wane with age.

In these experiments, the alveolar enlargement after Dex treatment, compared to control mice, was observed even in adult mice (P200). However, comparing the young and adults, in the Dex groups, adult mice had shorter $L_{\mathrm{m}}$ values than young mice, which fact suggested that the enlarged alveoli healed naturally with age in mice at least after about P90. Also, in the control groups, adult mice had longer $L_{\mathrm{m}}$ than 
young mice (Figs. 3, 5). With these factors taken into consideration, additional research is needed under other experimental conditions such as higher doses or longer treatment period to clarify the clinically practical effect of SV on emphysema.

\section{CONCLUSION}

The alveoli damaged by Dex treatment are recovered after administration of SV at a dose of $4 \mu \mathrm{g} / \mathrm{mouse} / \mathrm{d}$ i.p. or $20 \mu \mathrm{g} /$ mouse/d orally for $10 \mathrm{~d}$ to young model mice. The alveolar recovery after SV depends on exposure in plasma regardless of the administration route. On the other hand, in adult mice the recovery is not sufficient after i.p. administration at a dose of $4 \mu \mathrm{g} / \mathrm{mouse} / \mathrm{d}$.

Acknowledgment We would like to thank Dr. Donald Hinman for scientific advice and editing the manuscript.

Conflict of Interest The authors declare no conflict of interest.

\section{REFERENCES}

1) Murakami $S$, Nagaya $N$, Itoh $T$, Iwase $T$, Fujisato $T$, Nishioka $K$, Hamada K, Kangawa K, Kimura $H$. Adrenomedullin regenerates alveoli and vasculature in elastase-induced pulmonary emphysema in mice. Am. J. Respir. Crit. Care Med., 172, 581-589 (2005).

2) Fortunato G, Vidal DT, Klein W, Neto A, Angrizani A, Vasconcelos JF, Kaneto C, Souza BS, Ribeiro-dos-Santos R, Soares MB, Macambira SG. Recovery of pulmonary structure and exercise capacity by treatment with granulocyte-colony stimulating factor (G-CSF) in a mouse model of emphysema. Pulm. Pharmacol. Ther., 27, 144-149 (2014).

3) Sakai H, Horiguchi M, Ozawa C, Akita T, Hirota $K$, Shudo $K$, Terada H, Makino K, Kubo H, Yamashita C. Pulmonary administration of Am80 regenerates collapsed alveoli. J. Control. Release, 196, 154-160 (2014).

4) Massaro GD, Massaro D. Retinoic acid treatment abrogates elastase-induced pulmonary emphysema in rats. Nat. Med., 3, 675-677 (1997).

5) Lee JH, Lee DS, Kim EK, Choe KH, Oh YM, Shim TS, Kim SE, Lee YS, Lee SD. Simvastatin inhibits cigarette smoking-induced emphysema and pulmonary hypertension in rat lungs. Am. J. Respir. Crit. Care Med., 172, 987-993 (2005).

6) Takahashi S, Nakamura H, Seki M, Shiraishi Y, Yamamoto M, Furuuchi M, Nakajima T, Tsujimura S, Shirahata T, Nakamura
M, Minematsu N, Yamasaki M, Tateno H, Ishizaka A. Reversal of elastase-induced pulmonary emphysema and promotion of alveolar epithelial cell proliferation by simvastatin in mice. Am. J. Physiol. Lung Cell. Mol. Physiol., 294, L882-L890 (2008).

7) Corsini A, Maggi FM, Catapano AL. Pharmacology of competitive inhibitors of HMG-CoA reductase. Pharmacol. Res., 31, 9-27 (1995).

8) Davis ME, Korn MA, Gumucio JP, Harning JA, Saripalli AL, Bedi A, Mendias CL. Simvastatin reduces fibrosis and protects against muscle weakness after massive rotator cuff tear. J. Shoulder Elbow Surg., 24, 280-287 (2015).

9) Hsu M, Muchova L, Morioka I, Wong RJ, Schröder H, Stevenson DK. Tissue-specific effects of statins on the expression of heme oxygenase-1 in vivo. Biochem. Biophys. Res. Commun., 343, 738-744 (2006).

10) Kim SE, Thanh Thuy TT, Lee JH, Ro JY, Bae YA, Kong Y, Ahn JY, Lee DS, Oh YM, Lee SD, Lee YS. Simvastatin inhibits induction of matrix metalloproteinase-9 in rat alveolar macrophages exposed to cigarette smoke extract. Exp. Mol. Med., 41, 277-287 (2009).

11) Keddissi JI, Younis WG, Chbeir EA, Daher NN, Dernaika TA, Kinasewitz GT. The use of statins and lung function in current and former smokers. Chest, 132, 1764-1771 (2007).

12) Lawes CM, Thornley S, Young R, Hopkins R, Marshall R, Chan WC, Jackson G. Statin use in COPD patients is associated with a reduction in mortality: a national cohort study. Prim. Care Respir. J., 21, 35-40 (2012).

13) Kamei M, Miyajima A, Fujisawa M, Matsuoka Y, Hirota T. Effects of postnatal dexamethasone treatment on mRNA expression profiles of genes related to alveolar development in an emphysema model in mice. J. Toxicol. Sci., 39, 665-670 (2014).

14) Miyajima A, Ohashi $\mathrm{H}$, Fujishiro A, Matsuoka Y, Hiramatsu A, Hirota T. Effects of all trans-retinoic acid on alveolar regeneration in dexamethasone-induced emphysema models and its relationship to exposure in ICR and FVB mice. Biol. Pharm. Bull., 39, 927-934 (2016).

15) Dunnill MS. Quantitative methods in the study of pulmonary pathology. Thorax, 17, 320-328 (1962).

16) Germershausen JI, Hunt VM, Bostedor RG, Bailey PJ, Karkas JD, Alberts AW. Tissue selectivity of the cholesterol-lowering agents lovastatin, simvastatin and pravastatin in rats in vivo. Biochem. Biophys. Res. Commun., 158, 667-675 (1989).

17) Hasunuma $T$, Tohkin M, Kaniwa N, Jang IJ, Yimin C, Kaneko M, Saito Y, Takeuchi M, Watanabe H, Yamazoe Y, Uyama Y, Kawai S. Absence of ethnic differences in the pharmacokinetics of moxifloxacin, simvastatin, and meloxicam among three East Asian populations and Caucasians. Br. J. Clin. Pharmacol., 81, 1078-1090 (2016). 